on behalf of a new idea. Each time the issue at stake has been fundamental-the acceptance or rejection of new knowledge, revolutionising our understanding of man's place in Nature. Each time the repercussions, arousing partisanship and controversy, have reverberated along the whole cultural front. Such a situation developed in the middle of the nineteenth century when the battle for evolution reached its climax, and Press, platform and pulpit resounded to the noise of strife. The centre of that struggle was, of course, T. H. Huxley, and his activities brought him into contact with the whole intellectual life of the period-scientific, literary, philosophic and religious. Probably more than any other man of that century, the threads of cultural life crossed him from all directions.

Two years ago, when Dr. Leonard Huxley died, there were found among his papers more than three thousand of his father's letters. A remarkable, and in many ways a unique collection, including hundreds of letters from Darwin, Lyell, Faraday, Francis Galton, J. S. Mill, Skeat, Lecky, Hæckel, Herbert Spencer, Bentham, Browning, Tennyson, Jane and Thomas Carlyle, Pusey, etc., they represent a verit. able cross-section of cultural life at a critical epoch in history. The Imperial College of Science, in whose 'Huxley Building' he carried through most of his active work, is endeavouring to acquire this collection for the Huxley Museum, and in order to raise the necessary $£ 2,500$ is appealing to public subscription. The object is to maintain the collection intact and to house it in such a manner as to make it accessible to interested students of the period; for, once the letters are dispersed, the loss will be inestimable. It is in their unity that the collection exhibits one of its most valuable features. It is much to be hoped that the generation that has benefited so greatly from the result of Huxley's efforts will ensure that this necessary task is carried to a successful conclusion. Contributions should be sent to the Secretary, Imperial College of Science and Technology, South Kensington, London, S.W.7.

\section{British Dependencies and Mandated Territories in Africa}

ANY anxiety which may have been aroused by tentative suggestions relating to a future redistribution of Colonies and Mandated Territories in Africa, to which reference was made in NATURE of February 15 (see p. 249), should be dispelled, at least for the present, by the very definite pronouncement made by Mr. J. H. Thomas in the House of Commons on February 12, which stated in precise terms that no such proposals would be entertained. It is reported, however, that some misgiving is still felt in East Africa, and it is expected by leaders of the German movement in Tanganyika, according to a dispatch from the Nairobi correspondent of The Times in the issue of February 15, that Herr Hitler will make "a precise and firm demand within a few months". The same dispatch quotes from the East African Standard a passage to the effect that while the Colonial lands are theoretically the possessions of the Government, their future is not merely a matter for international negotiation. They are the inalienable homes of millions of people residing in, and developing them, who are wards of the British race. So far as concerns the Mandated Territories only, it might be argued on the other side that the mandate recognises these inalienable rights of the inhabitants, irrespective of the power in whose hands it may be vested. Past colonial history, however, and the conduct of ad. ministration by the mandatory powers since they accepted the responsibility, shows on an impartial view that under no Government, not even excepting the present administration of the Belgian Congo, of which too little has been heard, has so near an approach been made as in the British Territories to a complete adaptation of the methods of administra. tion and of the efforts to develop the civic and social capacities of the individual to the cultural status of the African as revealed in the scientific study of his institutions.

\section{The Galactic Nebulæ}

Mr. J. H. Rernolds delivered his presidential address to the Royal Astronomical Society on February 14, taking as his subject the "Galactic Nebulæ". At the moment, it may be said that the limelight of spectacular interest shines more strongly on the extragalactic nebulæ than on those nebulæ, more properly so called, which are to be found in our own system, although they present numerous features of great interest. They appear to be actual clouds, and are seen as dark patches in which the background of faint stars is partly or wholly obscured, unless the cloud is illuminated by an adjacent or interior star. If the illuminating star is of early type, the nebula shows a fluorescent emission spectrum excited by the ultra-violet light of the star; but if the latter is late in type, the nebula simply reflects the light. Among the galactic nebulæ are numbered the planetary nebulæ, which are now considered to have originated as gaseous shells emitted by novæ; but no planetary nebula has been found within eight degrees of the position of Tycho Brahe's very bright nova of 1572. Mr. Reynolds dealt with the nature of the dust which causes the colour excess of stars behind clouds and reflects the light of late type stars ; owing to the low temperature of interstellar space, the material must be frozen solid, and may consist of particles of frozen water or solid ammonia.

\section{Training of Industrial Physicists}

AN informal discussion on "The Training of Industrial Physicists" was held under the auspices of the Institute of Physics in the rooms of the Royal Society on February 11. Among the 180 persons present were representatives of nearly every univer. sity and college in Great Britain and Ireland, of firms employing physicists, and of research associations and Government establishments. The fact that so many distinguished representatives attended is in itself a clear demonstration of the importance of the subject. The opening speakers were Mr. A. P. M. Fleming, of the Metropolitan-Vickers Electrical Co., Ltd. ; Dr. W. H. Hatfield, of the Brown.Firth 
Research Laboratories; Mr. C. C. Paterson, of the General Electric Co., Ltd.; Prof. R. Whiddington, of the University of Leeds; Dr. R. H. Pickard, of the British Cotton Industry Research Association; and Prof. J. A. Crowther, of the University of Reading. After the tea interval, the meeting was opened for general discussion. The important suggestions and comments made at the meeting and in writing are receiving the most careful consideration of the Board of the Institute, which it is anticipated will issue a memorandum on the subject in due course.

\section{Salmon and Freshwater Fisheries}

INFORMaTION given in the Report for the Year 1934 of the Ministry of Agriculture and Fisheries Salmon and Freshwater Fisheries (H.M. Stationery Office, $1 s$. net) shows that, on the whole, despite the prolonged period of drought during the summer months of that year, no disasters of a widespread character took place. The droughty conditions have, however, inevitably affected the catch of fish to a certain extent and led to incidents of mortality from pollution of one kind or another. Although the mortality of fish attributable to furunculosis was comparatively slight, the Report wisely stresses the necessity for no relaxation of vigilance over the dangers of this disease and states that "it is regrettable that the Diseases of Fish Bill, after passing through the House of Lords, failed, owing to congestion of business in the House of Commons, to become law". There is evidence in the Report that increasing attention is being paid to problems of pollution which affect not only the fisheries, but also the use of rivers for water supply and as amenities for the general public. The appointment of an Inland Water Survey Committee will, it is hoped, produce additional information of value for the study of fishery problems by the gauging of streams and correlation of their flow with rainfall. It is satisfactory to note that the large amounts spent on sewage disposal during the last few years appear to be benefiting many rivers. There is, however, still much work to be done in this direction, and it is pointed out that sewage was probably the cause of more cases of fish destruction than resulted from industrial effluents.

\section{Research in the Electrical Industry}

THE main object of the British Electrical and Allied Industries Research Association, 15 Savoy Street, W.C.2 (the E.R.A.), is the co-operation of all sections of the electrical industry and of all those associated with it, in the general interests, of the industry and in the national interest. The sections include manufacturers of electric plant, those who supply electricity, those who make extensive use of it and scientific and technical investigators. The desired results, namely, industrial expansion and public benefit, can only be attained by team work of the highest order. The Association is well supported by the industries affected. During the last five years, the income has increased from $£ 31,600$ to $£ 65,840$. The main work done is to increase the efficiency and trustworthiness of electrical apparatus and of electrical supply. A reduction of cost is for the public benefit, and this can be achieved by expanding the field of utility and increasing the use and demand. Among other researches carried out was one on the thermal stability and ignitability of dielectrics. A range of standard heat sources was devised to simulate the conditions which occur in practice. The method of applying those heat sources when testing insulating materials for resistance to applied heat and the grading of them is described in a new report (Ref. $L / 64$ ) issued during the year. A novel feature of interest is the standard flame, produced by a spirit burner of the Barthel type, which is reproducible to a degree of accuracy not possible with the Méker gas burner which it replaces. An extension of this work is in progress on the behaviour of ignitable materials under different ambient conditions, such as draught, with the object of devising means whereby self-extinguishing materials may be graded to better advantage.

\section{Sixth International Congress for Scientific Management}

THE Proceedings of the Sixth International Con. gress for Scientific Management, which have now been published (London: P. S. King and Son, Ltd.), completes the series of seven volumes containing the papers and speeches at the Congress. The six volumes issued prior to the Congress contained the papers to be presented at the various sectional meetings. The final volume includes reports on the actual discussions, and the excellent summaries of the rapporteurs give epitomes of the matter contained in the previous volumes. Full reports are given of the speeches at the first plenary sessions when "Management Problems arising from Government Intervention" were discussed. In the Educational and Training Section, the scientific worker will find much that is of interest in the discussions on sources of recruitment and methods of selection, which ranged over a wide field of personnel problems, and on objects and methods of training and further education, or on the avoidance of excess and waste of personnel selected and trained for high administrative positions. The wider use in administrative work of technical and scientific workers possessing administrative ability, while an urgent need in industry as in Government to-day, is only part of the general question of encouraging the development and securing the best selection of those possessing real administrative powers. The second plenary session, on the simplification of data, the place of statistics and the standardisation of terms, as well as various discussions in the manufacturing and agricultural sections, are also of considerable interest; for example, those on scientific methods applied to works management and on production control. For a volume designed as a permanent record, it is a pity that the subject index is so meagre.

\section{Compressed Gas as a Fuel for Motor Transport}

ON December 13, Mr. Robert Cook read a paper on "Compressed Gas as a Fuel for Motor Transport" before the East Midland Section of the Institute of Fuel and the Society of Chemical Industry at 